\title{
Evaluation of a New Remote Handling Design for High Throughput Annular Centrifugal Contactors
}

David H. Meikrantz

Troy G. Garn

Jack D. Law

Lawrence L. Macaluso

September 2009

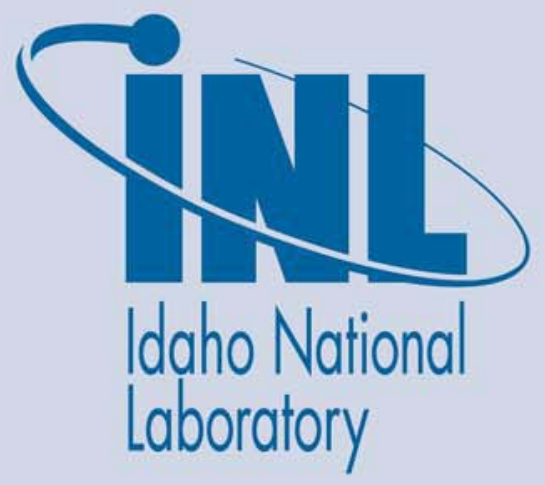

The INL is a U.S. Department of Energy National Laboratory operated by Battelle Energy Alliance 
INL/EXT-09-16824

\title{
Evaluation of a New Remote Handling Design for High Throughput Annular Centrifugal Contactors
}

\author{
David H. Meikrantz \\ Troy G. Garn \\ Jack D. Law \\ Lawrence L. Macaluso ${ }^{1}$ \\ ${ }^{1}$ Advanced Machine Design
}

September 2009

Idaho National Laboratory

Idaho Falls, Idaho 83415

http://www.inl.gov

Prepared for the

U.S. Department of Energy

Office of Nuclear Energy

Under DOE Idaho Operations Office

Contract DE-AC07-05ID14517 


\section{Evaluation of a New Remote Handling Design for High Throughput Annular Centrifugal Contactors \\ Advanced Fuel Cycle Initiative}

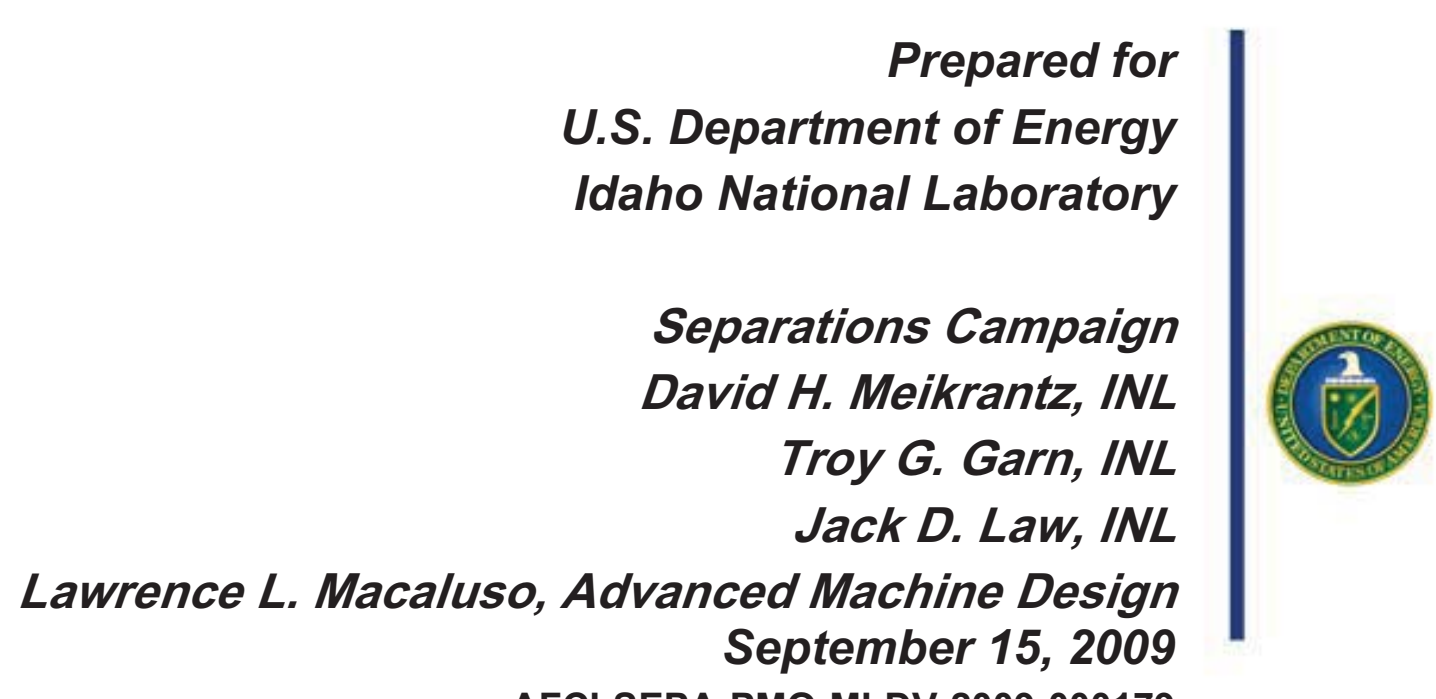

AFCI-SEPA-PMO-MI-DV-2009-000179 


\section{DISCLAIMER}

This information was prepared as an account of work sponsored by an agency of the U.S. Government. Neither the U.S. Government nor any agency thereof, nor any of their employees, makes any warranty, expressed or implied, or assumes any legal liability or responsibility for the accuracy, completeness, or usefulness, of any information, apparatus, product, or process disclosed, or represents that its use would not infringe privately owned rights. References herein to any specific commercial product, process, or service by trade name, trade mark, manufacturer, or otherwise, does not necessarily constitute or imply its endorsement, recommendation, or favoring by the U.S. Government or any agency thereof. The views and opinions of authors expressed herein do not necessarily state or reflect those of the U.S. Government or any agency thereof. 


\section{SUMMARY}

Advanced designs of nuclear fuel recycling plants are expected to include more ambitious goals for aqueous based separations including; higher separations efficiency, high-level waste minimization, and a greater focus on continuous processes to minimize cost and footprint. Therefore, Annular Centrifugal Contactors (ACCs) are destined to play a more important role for such future processing schemes. Previous efforts defined and characterized the performance of commercial $5 \mathrm{~cm}$ and $12.5 \mathrm{~cm}$ single-stage ACCs in a "cold" environment. The next logical step, the design and evaluation of remote capable pilot scale ACCs in a "hot" or radioactive environment was reported earlier. This report includes the development of remote designs for ACCs that can process the large throughput rates needed in future nuclear fuel recycling plants. Novel designs were developed for the remote interconnection of contactor units, clean-in-place and drain connections, and a new solids removal collection chamber. A three stage, $12.5 \mathrm{~cm}$ diameter rotor module has been constructed and evaluated for operational function and remote handling in highly radioactive environments. This design is scalable to commercial CINC ACC models from V-05 to V-20 with total throughput rates ranging from 20 to 650 liters per minute.

The V-05R three stage prototype was manufactured by the commercial vendor for ACCs in the U.S., CINC mfg. It employs three standard V-05 clean-in-place (CIP) units modified for remote service and replacement via new methods of connection for solution inlets, outlets, drain and CIP. Hydraulic testing and functional checks were successfully conducted and then the prototype was evaluated for remote handling and maintenance suitability. Removal and replacement of the center position V-05R ACC unit in the three stage prototype was demonstrated using an overhead rail mounted PaR manipulator. This evaluation confirmed the efficacy of this innovative design for interconnecting and cleaning individual stages while retaining the benefits of commercially reliable ACC equipment for remote applications in the nuclear industry. Minor modifications and suggestions for improved manual remote servicing by the remote handling specialists were provided but successful removal and replacement was demonstrated in the first prototype.

\section{ACKNOWLEDGMENTS}

This work was performed under the auspices and financial support of the United States Department of Energy, Office of Nuclear Energy, Science and Technology through contract DE-AC07-05ID14517.

The authors would like to acknowledge the remote equipment and operational skills of Kevin Croft of the INL Robotics and Intelligent Systems Department. Kevin operated the PaR gantry robot in manual mode during our remote evaluations and provided valuable insight with regard to the contemporary capabilities of the PaR XR-100. Furthermore, we wish to thank Jimmy Blaylock of the INL Materials and Fuels Complex Remote Mock-up Shop for his invaluable input and unmatched skill and experience with manual remote handling design and operations. 


\section{CONTENTS}

SUMMARY iii

ACRONYMS vii

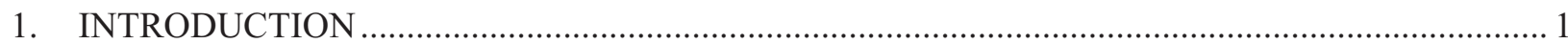

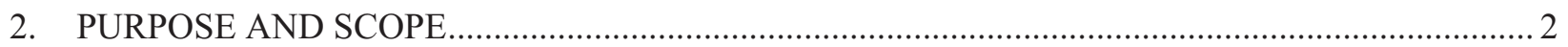

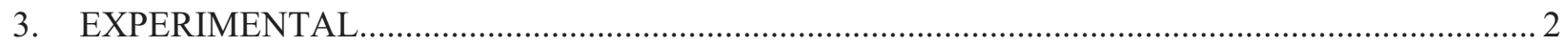

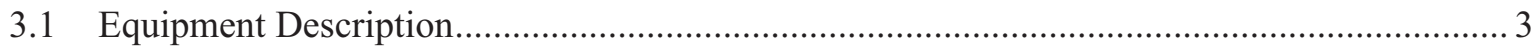

3.1.1 Design Modifications for Remote Applications .................................................. 3

3.1.2 Mechanical and Hydraulic Performance Evaluation .................................................. 8

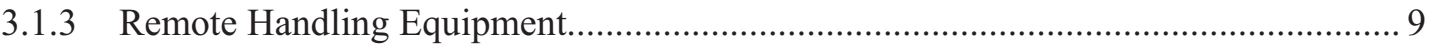

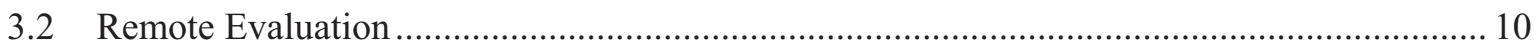

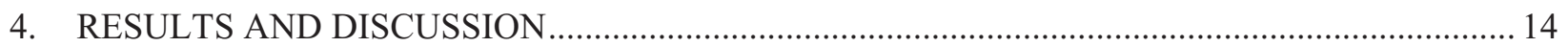

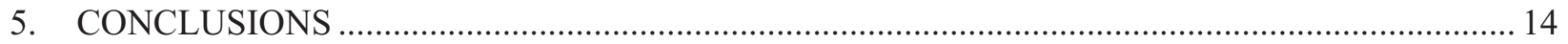

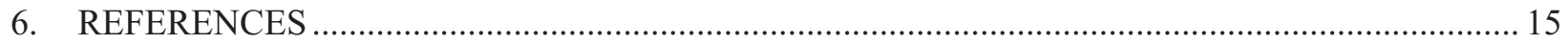

\section{FIGURES}

Figure 1 Prototype three-stage CINC V-05R module and remote control panel .......................................2

Figure 2 Drawing of remote V-05R $12.5 \mathrm{~cm}$ rotor ACC assembly, front view ....................................... 4

Figure 3 Drawing of remote V-05R $12.5 \mathrm{~cm}$ rotor ACC assembly, side view with fluid

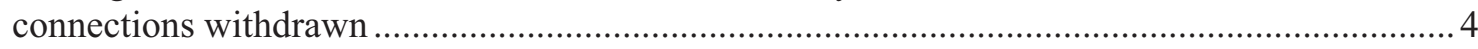

Figure 4 New design of remote fluid transfer connection for ACCs .................................................. 5

Figure 5 Pneumatic lift and connection design for CIP and drain, shown in disengaged position .............. 5

Figure 6 Pneumatic lift and connection design for CIP and drain, shown engaged for contactor

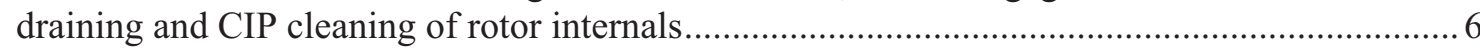

Figure 7 Design for remote stage contactor removal showing a unit partially withdrawn (from an earlier version frame) with guide pins shown and fluid connections retracted .......................... 6

Figure 8 Solids collector (green ring) located under modified contactor bottom plate (yellow) ................. 7

Figure 9 Lower sectional view of contactor showing solids collector, CIP connection on rotor tail

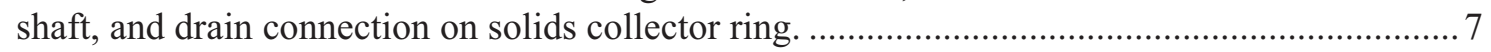

Figure 10 The PaR XR-100 gantry robot and nested 4350 remote manipulator tool .............................. 9

Figure 11 Removal of the middle unit with tapered locating pins visible on the frame ........................... 10

Figure 12 V-05R contactor unit removed from assembly ............................................................... 11

Figure $13 \mathrm{Re}$-installation with guide pins halfway engaged ........................................................... 11

Figure 14 Close up view of guide pins during contactor unit installation .............................................. 12 
Figure 15 Close up view of spring loaded capture bolts, left one engaged, right one disengaged ............. 12

Figure 16 Close up view of fluid transfer slide mechanism and o-ring connectors, disengaged............... 13

Figure 17 Close up view of the drain (left) and CIP (right) connections and pneumatic driven slide, disengaged 13

\section{TABLES}

Table 1 Detailed description of V-05R remote module and associated equipment. ................................. 3 


\section{ACRONYMS}

$\begin{array}{ll}\text { ACC } & \text { Annular Centrifugal Contactor } \\ \text { AFCI } & \text { Advanced Fuel Cycle Initiative } \\ \text { BCTC } & \text { Bonneville County Technology Center } \\ \text { CIP } & \text { Clean-In-Place } \\ \text { DOE } & \text { Department of Energy } \\ \text { EMM } & \text { electromechanical manipulators } \\ \text { GPM } & \text { gallons per minute } \\ \text { INL } & \text { Idaho National Laboratory } \\ \text { MSM } & \text { master-slave manipulators } \\ \text { PLC } & \text { Programmable Logic Controller } \\ \text { STC } & \text { Science and Technology Complex } \\ \text { VFD } & \text { variable frequency drive }\end{array}$




\section{AFCI SEPARATIONS CAMPAIGN EVALUATION OF REMOTE HANDLING DESIGN FOR HIGH THROUGHPUT ANNULAR CENTRIFUGAL CONTACTORS}

\section{INTRODUCTION}

Commercially available, mass produced, annular centrifugal contactors (ACCs) are currently utilized in a wide range of separations processes both industrially and in government for research, development, and production. Evaluation of these standard units, in support of the various nuclear fuel cycle and radioactive waste management goals, is continuing at the Idaho National Laboratory (INL) and other national laboratories within the Department of Energy (DOE) complex in support of the Advanced Fuel Cycle Initiative (AFCI). Commercially available ACCs have numerous advantages over custom fabricated units; lower cost, proven reliability, better availability, and multiple sizes designed for a wide range of process needs.

Previous testing of commercial ACCs at the INL focused on the evaluation of single-stage units. Hydraulic and mass transfer testing of commercial $5 \mathrm{~cm}$ and $12.5 \mathrm{~cm}$ single-stage units has been reported. $^{1,2,3}$ A reliability evaluation beginning in May 2006 of a $12.5 \mathrm{~cm}$ unit was conducted for almost three years without any noticeable mechanical change or service required. In addition, a solids collection and removal evaluation of a $12.5 \mathrm{~cm}$ unit equipped with CIP was also reported and found valuable for remote cleaning operations. ${ }^{4}$

To support equipment design for future nuclear fuel recycle pilot processing facilities, an interconnected three-stage $5 \mathrm{~cm}$ remote design module was completed. The module was designed to enable remote handling with typical reprocessing cell equipment such as master-slave (MSM) and electromechanical (EMM) manipulators. The ability to quickly and efficiently perform a change-out of a single-stage assembly from a multiple stage cascade while maintaining equilibrium in the cascade, minimizes process downtime, eliminates the need to drain and recycle and thus increases overall process efficiency. Two three-stage modules were constructed for experimental evaluations at the INL. One module was used for a hydraulic evaluation ${ }^{5}$ in the INL Engineering and Demonstration Facility located at the Science and Technology Complex (STC), and the second was used for the remote evaluation conducted at the INL Materials and Fuels Complex remote handling mockup facility. ${ }^{6}$ The $5 \mathrm{~cm}$ rotor-based contactor module was found to be well adapted to remote service with a motor/rotor changeout easily accomplished in only minutes and hydraulic performance unchanged from standard single unit results.

The next step in the program was to consider the designs of remote use adapted high throughput contactors that would be needed for production level operations. Standard commercial ACCs with rotors of $12.5 \mathrm{~cm}$ and larger employ a tail shaft, rotary seal, and bearing at the bottom end of the rotor for stability, strength, and reliability. However, this tail shaft assembly prevents the direct removal of a motor/rotor from the top as is typical done in the smaller pilot and laboratory scale ACCs. Therefore, either the rotor and related support at the upper housing region must be significantly modified or another means of removal for the standard design ACC must be developed. The second path was chosen to take advantage of the proven reliability of commercial ACC units and is adaptable to any high throughput unit. This report describes the design and subsequent testing of a first prototype $12.5 \mathrm{~cm}$ rotor-based contactor module and gives results from the hydraulic testing and remote evaluation performed at the INL. 


\section{PURPOSE AND SCOPE}

The purpose of this work is to evaluate the utility of the newly designed three stage remote $12.5 \mathrm{~cm}$ contactor module with typical shielded cell remote handling equipment. Remote designs of commercially viable equipment for nuclear fuel recycling are of interest to support use and maintenance in highly radioactive environments. Novel design concepts are first developed, prototype equipment fabricated, and then tested. Such evaluations are necessary to demonstrate the ability for remote handling equipment to effectively service and replace processing equipment. In addition, hydraulic tests to verify that modifications for remote use have no deleterious effect on equipment performance are needed. The information thus gained helps to define specific remote handling equipment requirements, further modifications or improvements to the remote design, and provides guidance toward next generation facility design. The purpose of this work is to evaluate the compatibility of the remote designed three stage V-05R module with reprocessing cell type handling equipment.

The scope of this evaluation includes: 1) performing both hydraulic verification of prototype equipment performance and 2) initial design evaluation of the ability to service and replace a single contactor from the three stage module using manually operated remote handling tools. Recommendations for the types of remote handling equipment required to service the prototype, as tested, and improvements to the remote design features are also provided by experts.

\section{EXPERIMENTAL}

A three-stage module was designed during FY 08 and constructed in FY 09 at CINC manufacturing, Carson City, NV. The module includes a remote control panel that includes pneumatic input for remote operation of CIP and drain connections, rotor speed controller adjustment, indicator lights, and an electrical shutdown switch. Figure 1 is a photograph of the module with control panel prior to shipment to the INL.

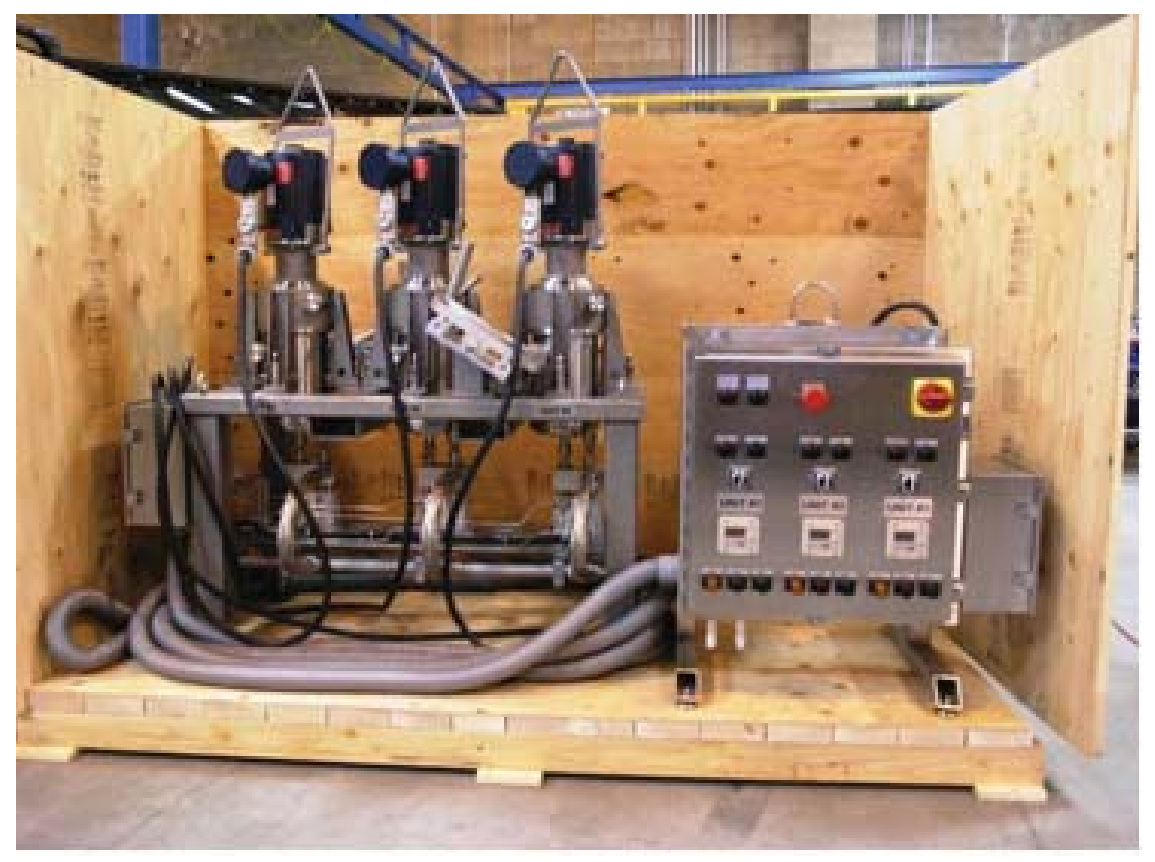

Figure 1 Prototype three-stage CINC V-05R module and remote control panel prior to shipment to the INL. 


\subsection{Equipment Description}

The three-stage remote module is composed of three Model V-05 CINC $12.5 \mathrm{~cm}$ rotor diameter ACCs with inter-stage connectivity via 1 inch stainless steel tubing and o-ring fittings. Sample and vent lines for all stage aqueous and organic discharge lines also employ 1 inch stainless steel tubing. Table 1 provides a detailed description of the remote module and associated equipment.

Table 1 Detailed description of V-05R remote module and associated equipment.

\begin{tabular}{ll}
\hline \multicolumn{1}{c}{ Contactor size } & \multicolumn{1}{c}{$12.5 \mathrm{~cm}(5$ in.) rotor O.D. } \\
\hline Materials of construction & Stainless steel: 316L ACC, 304 Frame \\
Rated capacity & $0.5-20 \mathrm{LPM}$ \\
Inlet/Outlet housing ports & Male 1.312 in. o-ring, tangential \\
Rotor motors & Leeson XP 2 hp, $(1.5 \mathrm{~kW}), 230 / 460 \mathrm{~V}, 3$ phase, 0-3450 \\
& rpm, Class 1, Div II, Group D \\
Rotor speed controllers & Yaskawa V7, 2hp (1.5kW) VFD with JVOP-140 digital \\
& operator \\
Configuration & Three-stage interconnected \\
Air supply pressure & $90-110$ psi \\
Power requirement & $208-240$ VAC, 3 phase, 30 amps \\
Control panel footprint $(\mathrm{L} \times \mathrm{D} \times \mathrm{H})$ approx. & 24 in. $\times 24$ in. $\times 36$ in. \\
Module footprint $(\mathrm{L} \times \mathrm{D} \times \mathrm{H})$ approx. & 44 in. $\times 22$ in. $\times 50$ in. \\
\hline
\end{tabular}

\subsubsection{Design Modifications for Remote Applications}

The three-stage module design incorporated a number of modifications to the original off-the-shelf contactor design. Design drawings are provided in the following figures as cited to illustrate the new modifications found in the prototype. This high volume ACC design assembly has been submitted for a U.S. Patent by Battelle Energy Alliance, the prime INL contractor. The significant design modifications are as follows:

- A new rigid frame was designed to hold the three contactor units in alignment, Figures 2,3

- A screw driven slide mechanism was employed with o-ring fittings to make interconnections of process streams between contactor stages, Figure 4

- Pneumatic actuated lift for making the CIP and drain connections for remote contactor rotor cleaning In addition, new self closing valves for the CIP and drain connections Figures 5,6

- Two guide pins were located on opposite sides of the contactor frame assembly for each unit enabling contactor reinsertion and alignment into frame using remote handling equipment, Figures 3,7

- The contactor bottom plate was modified by adding seven more drain holes and to include a solids collector plenum located below the normal process fluids flow path Figure 8,9

- All o-rings and seals were located on the removable contactor unit to facilitate service and replacement 


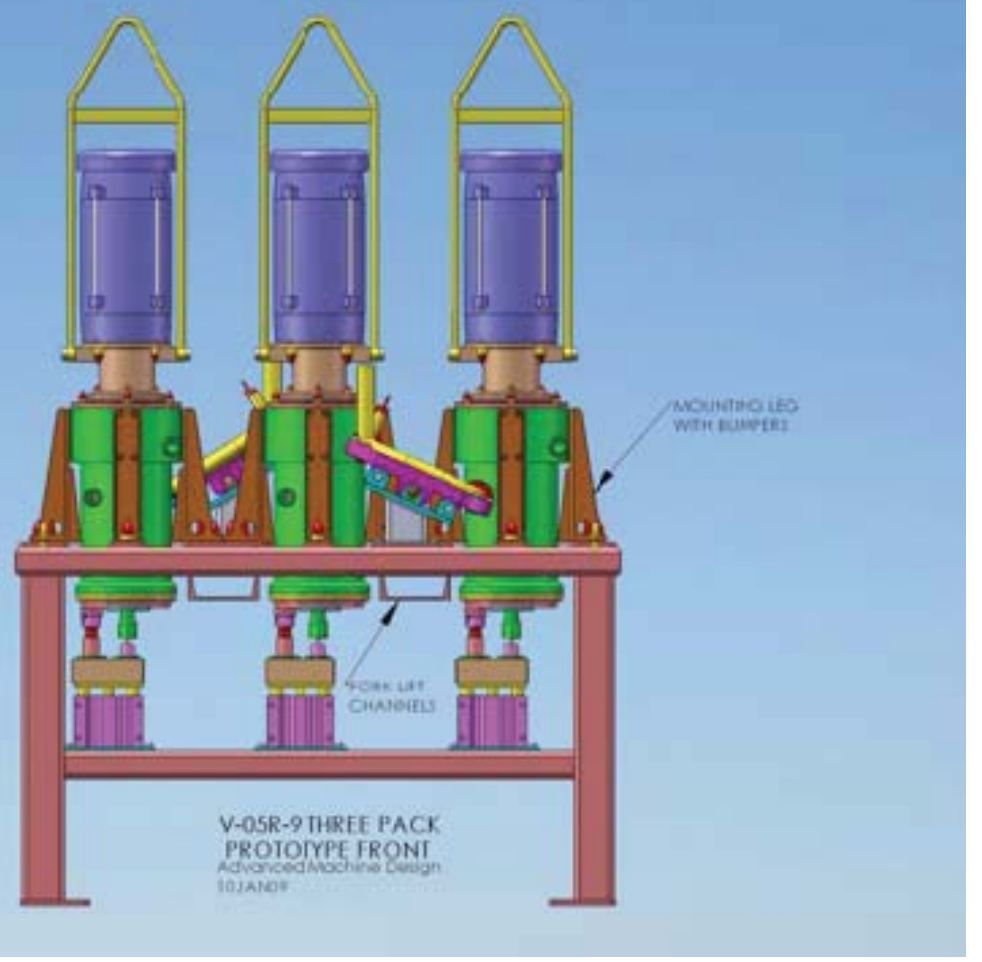

Figure 2 Drawing of remote $\mathrm{V}-05 \mathrm{R} 12.5 \mathrm{~cm}$ rotor $\mathrm{ACC}$ assembly, front view

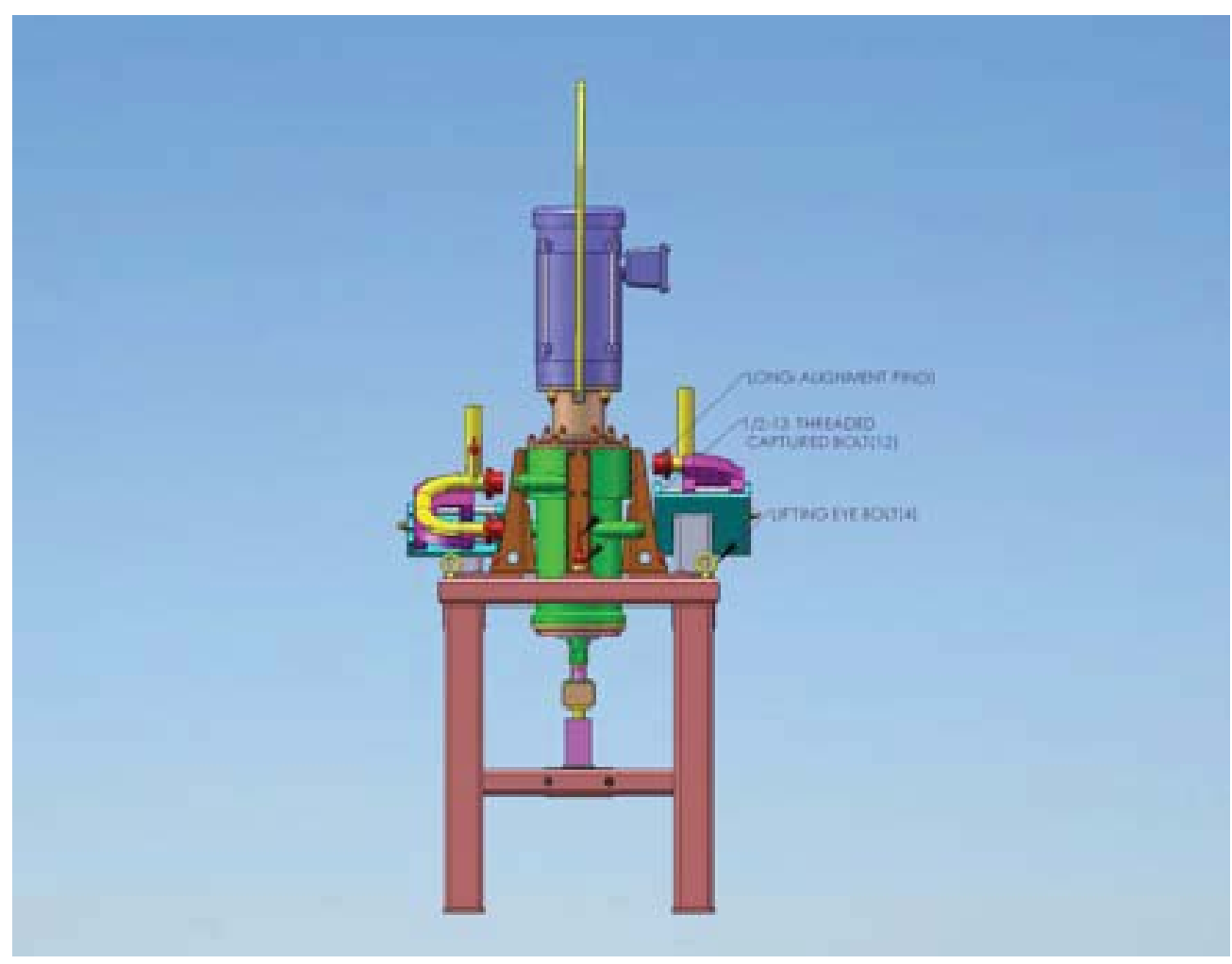

Figure 3 Drawing of remote $\mathrm{V}-05 \mathrm{R} 12.5 \mathrm{~cm}$ rotor $\mathrm{ACC}$ assembly, side view with fluid connections withdrawn 


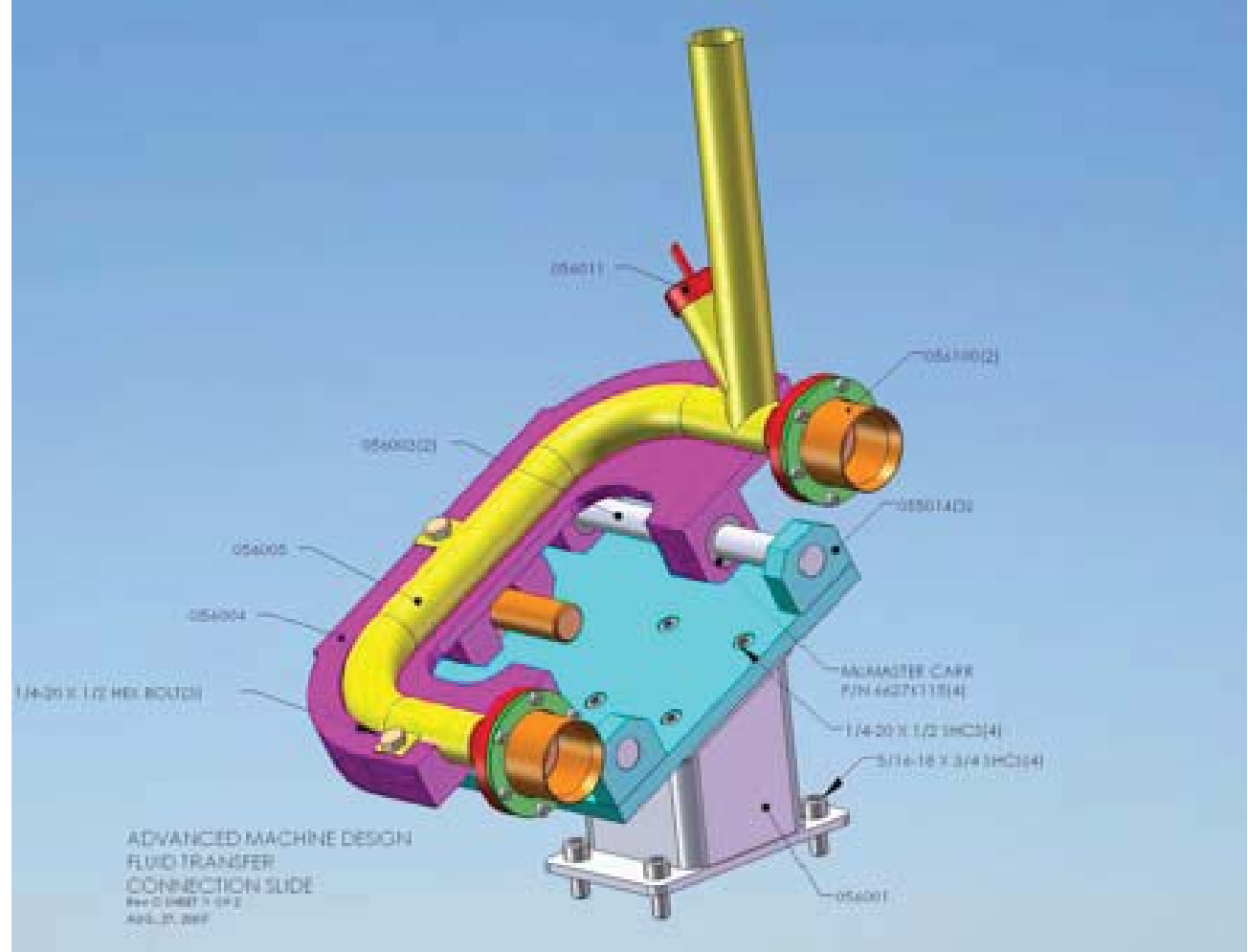

Figure 4 New design of remote fluid transfer connection for ACCs

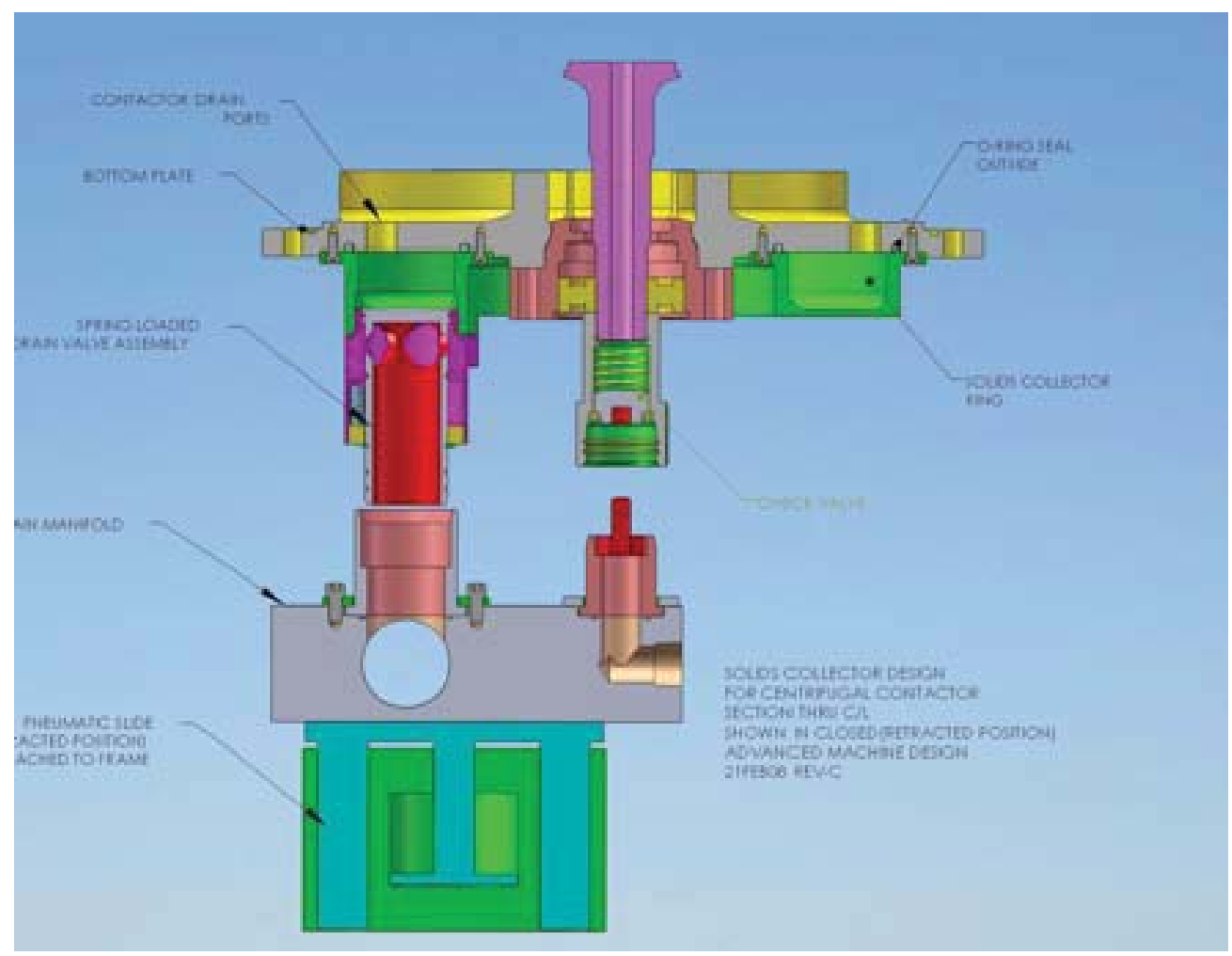

Figure 5 Pneumatic lift and connection design for CIP and drain, shown in disengaged position 


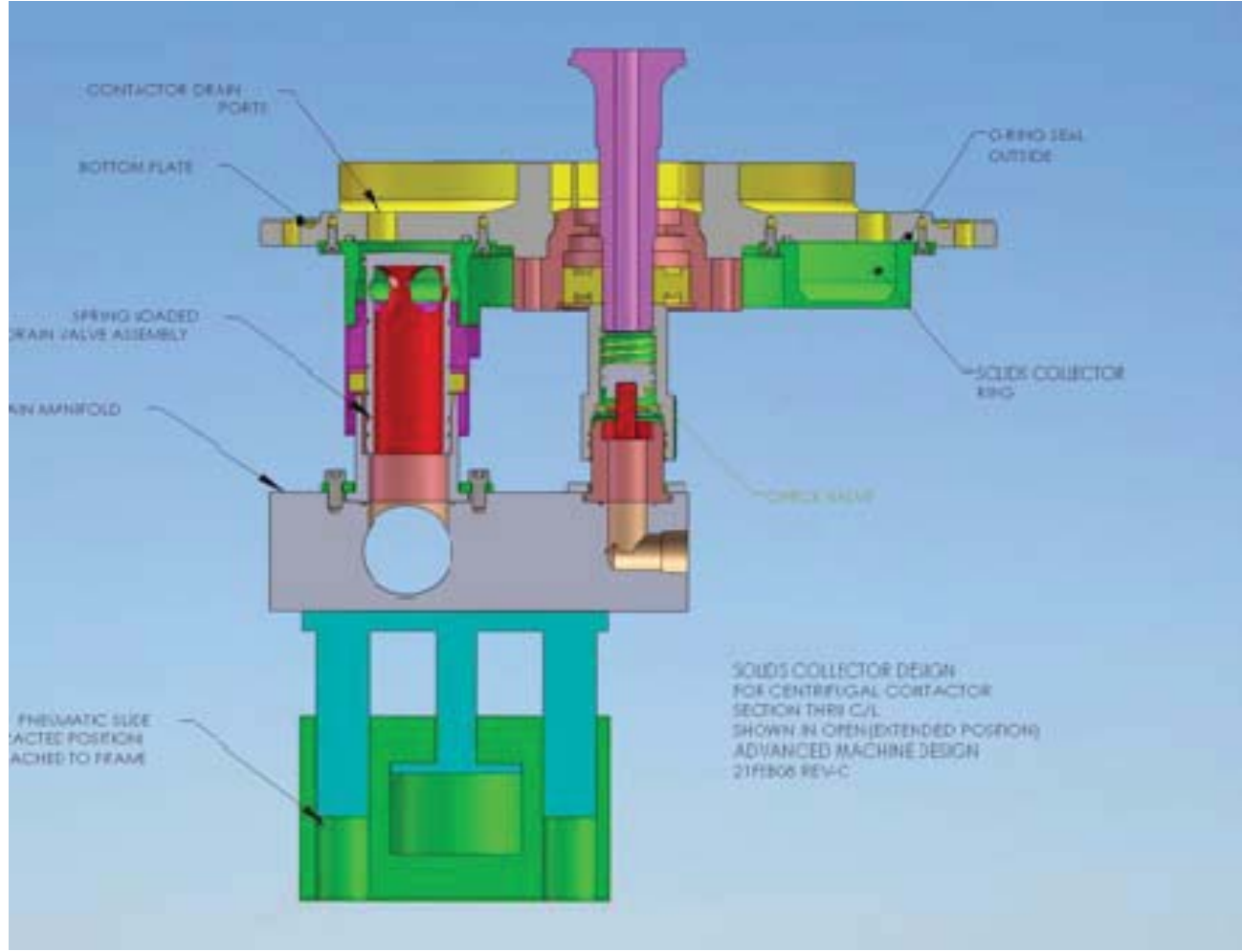

Figure 6 Pneumatic lift and connection design for CIP and drain, shown engaged for contactor draining and CIP cleaning of rotor internals

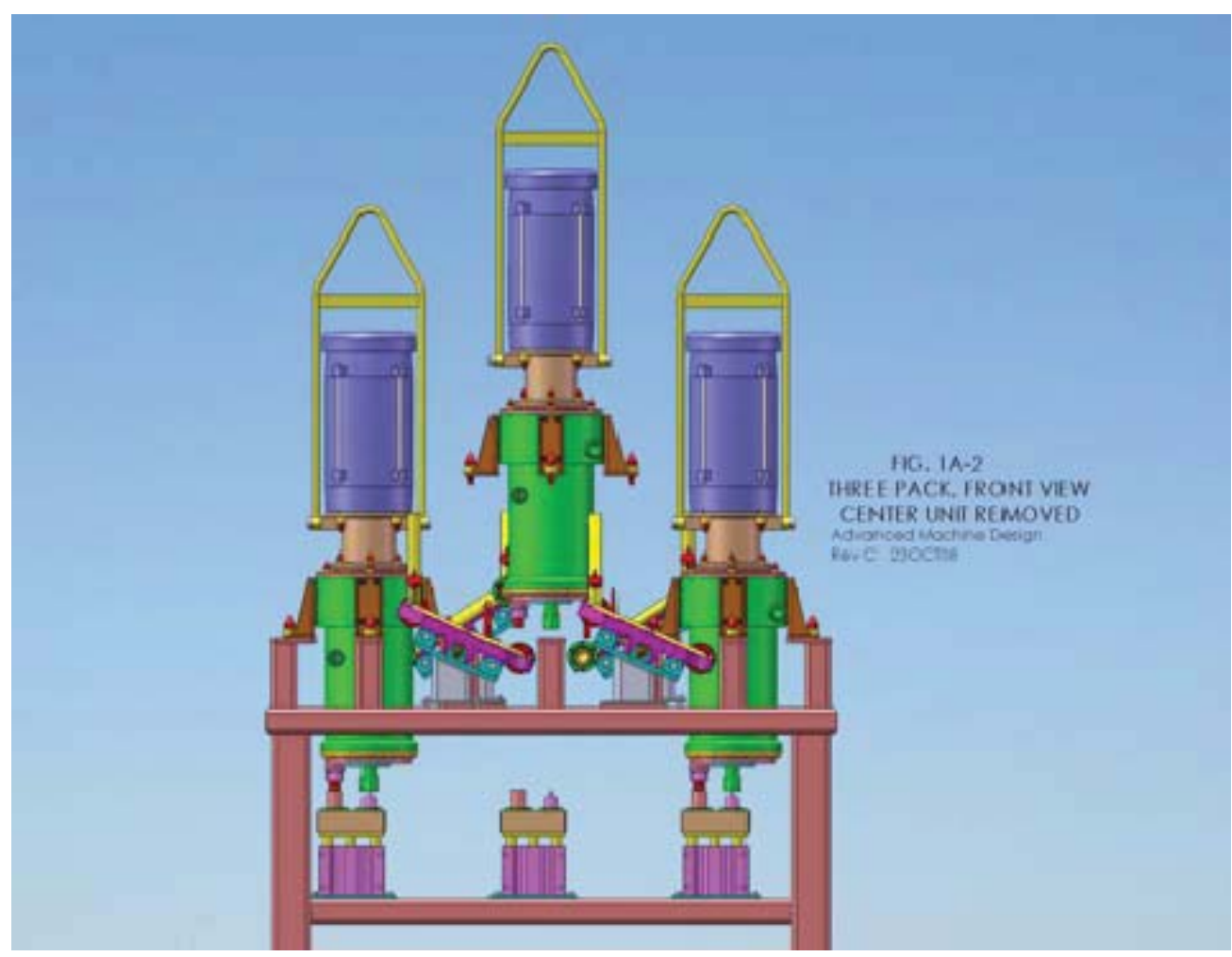

Figure 7 Design for remote stage contactor removal showing a unit partially withdrawn (from an earlier version frame) with guide pins shown and fluid connections retracted 


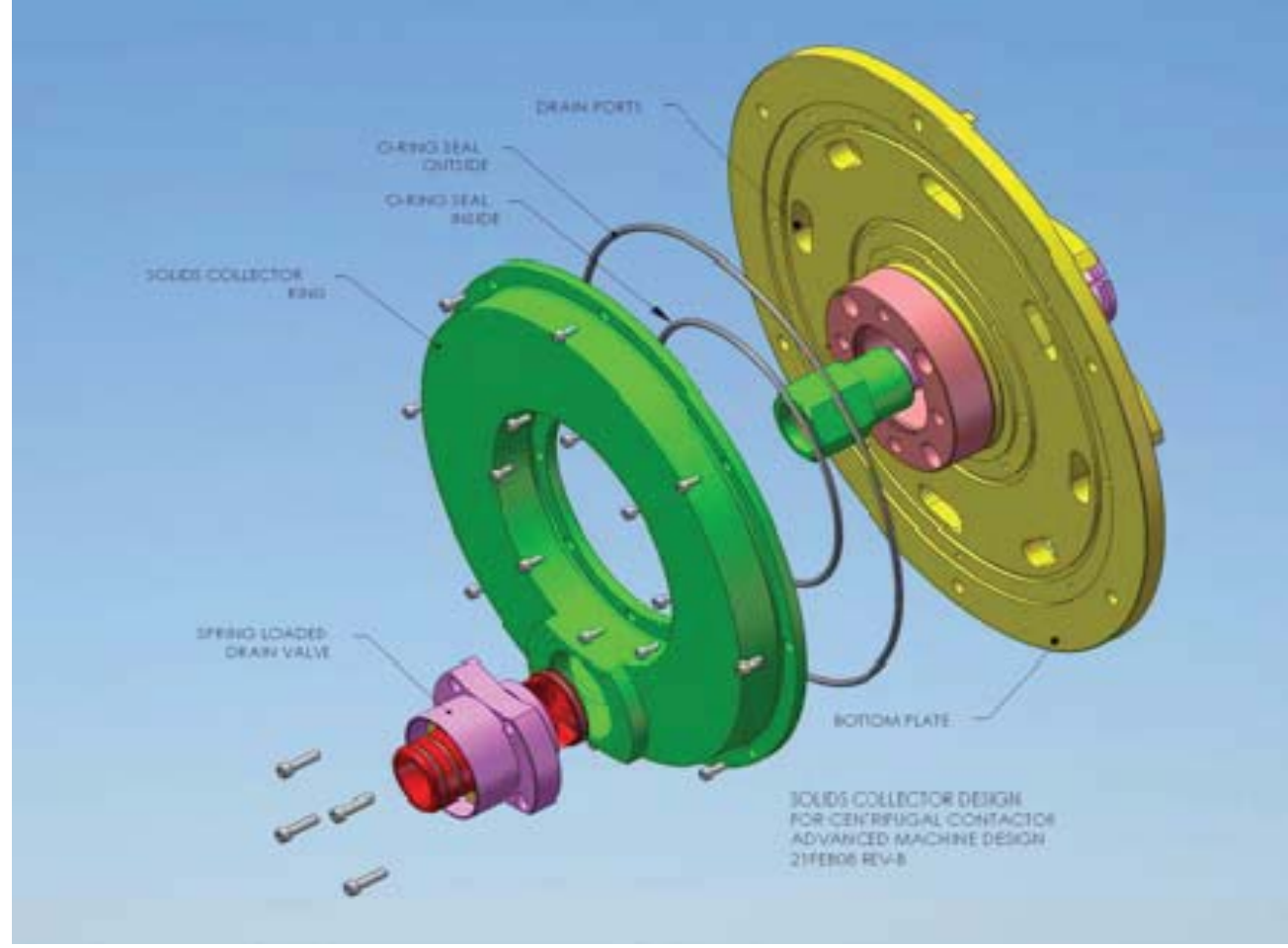

Figure 8 Solids collector (green ring) located under modified contactor bottom plate (yellow)

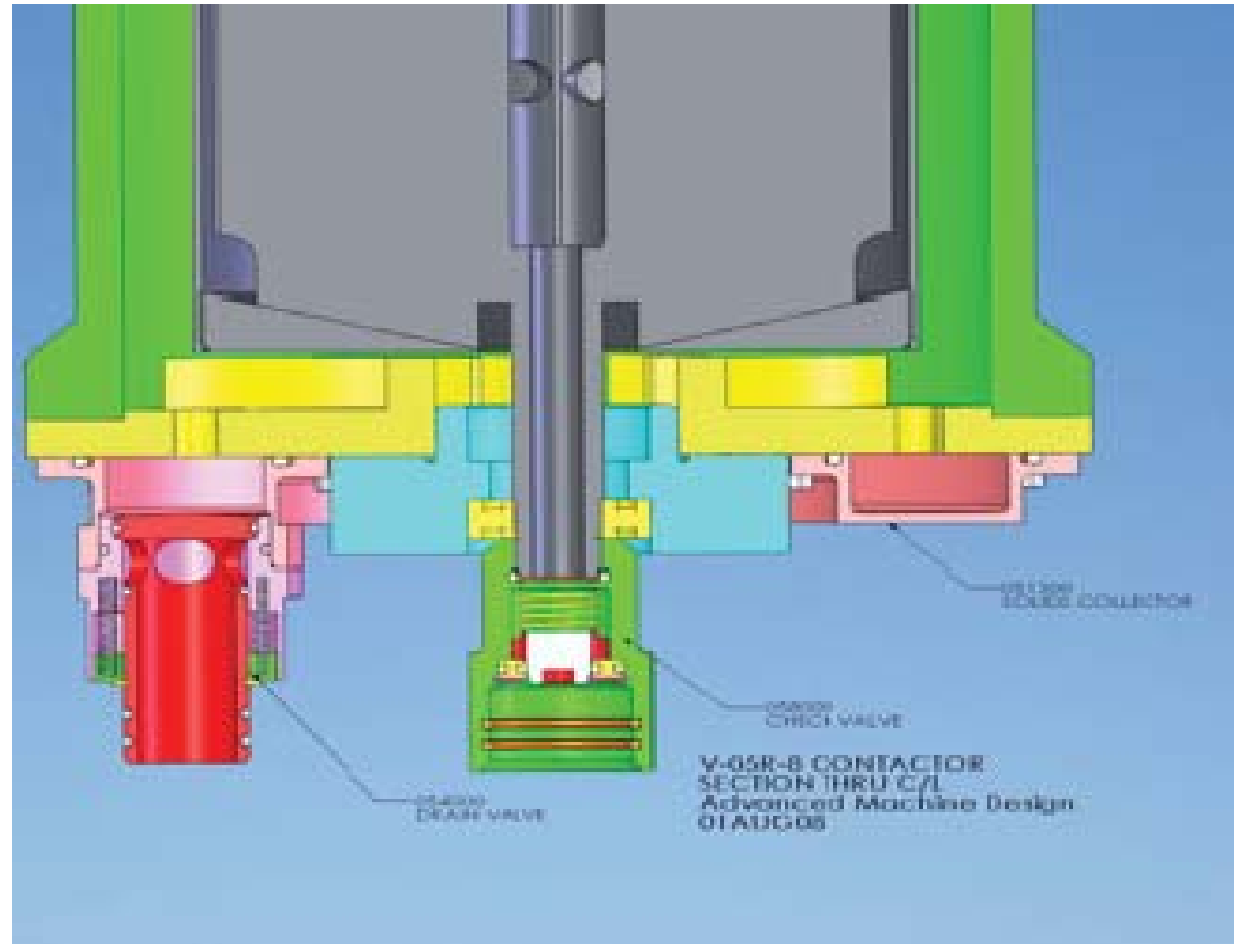

Figure 9 Lower sectional view of contactor showing solids collector, CIP connection on rotor tail shaft, and drain connection on solids collector ring. 
This design for high throughput remote use ACCs was intended to employ commercially available units with minimal functional design changes. The goal was to utilize industrial ACCs that have already received numerous design improvements, employ commercial bearings and seals, follow robust engineering principles, and exhibit proven reliability. Reliability of mechanical devices employed in shielded cells for nuclear fuel recycle processes is considered one of the most important attributes for successful operations. Numerous stages of contactors will be required to meet AFCI separations goals for each separations cycle, thus merely having units that are easily replaced but of low reliability is not acceptable. Modifications described here were prototyped using CINC V-05 ACCs but can be employed on any larger throughput unit as well.

\subsubsection{Mechanical and Hydraulic Performance Evaluation}

The completed prototype was functionally tested at the CINC facility in Carson City, NV prior to shipment to the INL. One of the authors and the mechanical designer, Larry Macaluso, was present to observe and evaluate and provided the details of the mechanical and hydraulic testing.

Mechanical testing of the fluid transfer slide designs and as fabricated assemblies were acceptable as both slides moved easily when the screw was turned, they also connected to and disconnected from the contactor smoothly. The contactor was filled with water and operated to verify that no leakage from the fluid transfer assemblies occurred. Next, the CIP drain slides were pneumatically actuated several times. All three assemblies moved smoothly, engaged and disengaged properly with each lower contactor connection, and showed no signs of leakage.

The contactor assembly and frame alignment was tested on the middle ACC by retracting the fluid transfer slides, disengaging the four spring loaded captive bolts that attach the contactor to the frame, and then lifting the middle contactor unit up and removing it from the assembly. The contactor was reinstalled by lowering until it engaged the two tapered guide pins and the lowered into place on the frame mounts. After engaging and tightening the four captive bolts, the fluid transfer slides were reconnected to the contactor inlet and outlets to verify alignment of the reinstalled unit. All connections were successfully engaged. The CIP and drain connections were also tested successfully for proper alignment.

The contactors were then tested using water as the heavy phase and kerosene as the lighter phase to verify that no leakage occurred at any of the newly designed connections and observe hydraulic performance at maximum flow rate. The three V-05R units were successfully tested at a counter current total flow rate of approximately five gpm using heavy phase 2.55 inch I.D. weirs with good phase separation. Hydraulic performance was normal and no leakage was observed from the fluid transfer slide connections or from the CIP and drain connections.

The final test was of the CIP connections, drain valve capacity, and flow performance of the center contactor using a CIP flush rate of five gpm and 40 psi. No leakage was observed and the size of the drain valve was sufficient to allow the gravity draining of the full flow rate. No unusual flow characteristics due to the solids collector ring addition or bottom plate modifications were observed.

One significant observation was made during the mechanical and hydraulic evaluation. No provisions were made in the control panel to prevent accidentally engaging the CIP/Drain valve slide while a particular contactor is operating. Mating the drain and CIP connections to the contactor during operation is not desirable and would likely cause damage to the contactor and associated components. Therefore, it was decided that a Programmable Logic Controller (PLC) be installed in the control panel, and integrated 
with the functions of the contactor and CIP drain slide control valves. The PLC would be programmed to prevent the CIP drain valve from engaging while the contactor rotor is turning. It was also programmed to assure that a complete mating was made with CIP drain slide and the contactor connections. Thus, the PLC was sourced, programmed and added to the control panel by CINC prior to shipment of the prototype to the INL

\subsubsection{Remote Handling Equipment}

Remote testing of the V-05R assembly was conducted at the Bonneville County Technology Center, bay 6 , at the INL. A state of the art PaR XR-100 gantry robot was available in the adjacent bay to support our remote handling testing. The robot is a 4 -axis $(\mathrm{X}, \mathrm{Y}, \mathrm{Z}$, and tool rotation) programmable gantry system that includes a telescoping mast and DeStaco remote interface for use with a wide variety of tools. It includes a PaR 4350 manipulator arm as one of the interchangeable tools that has a load capacity of 250 lbs. It was purchased in 2007. This is an intelligent system and is excellent for tele-operation and/or programmed routines. It has the capability to learn and reproduce coordinate locations to within .008 of an inch and would be a logical choice for maintaining a large number of ACCs with little or no direct operator assistance. The gantry system is rated and load tested to handle up to $4800 \mathrm{lb}$., sufficient to service even large modules of ACCs when required. A picture of the robot is provided in Figure 10.

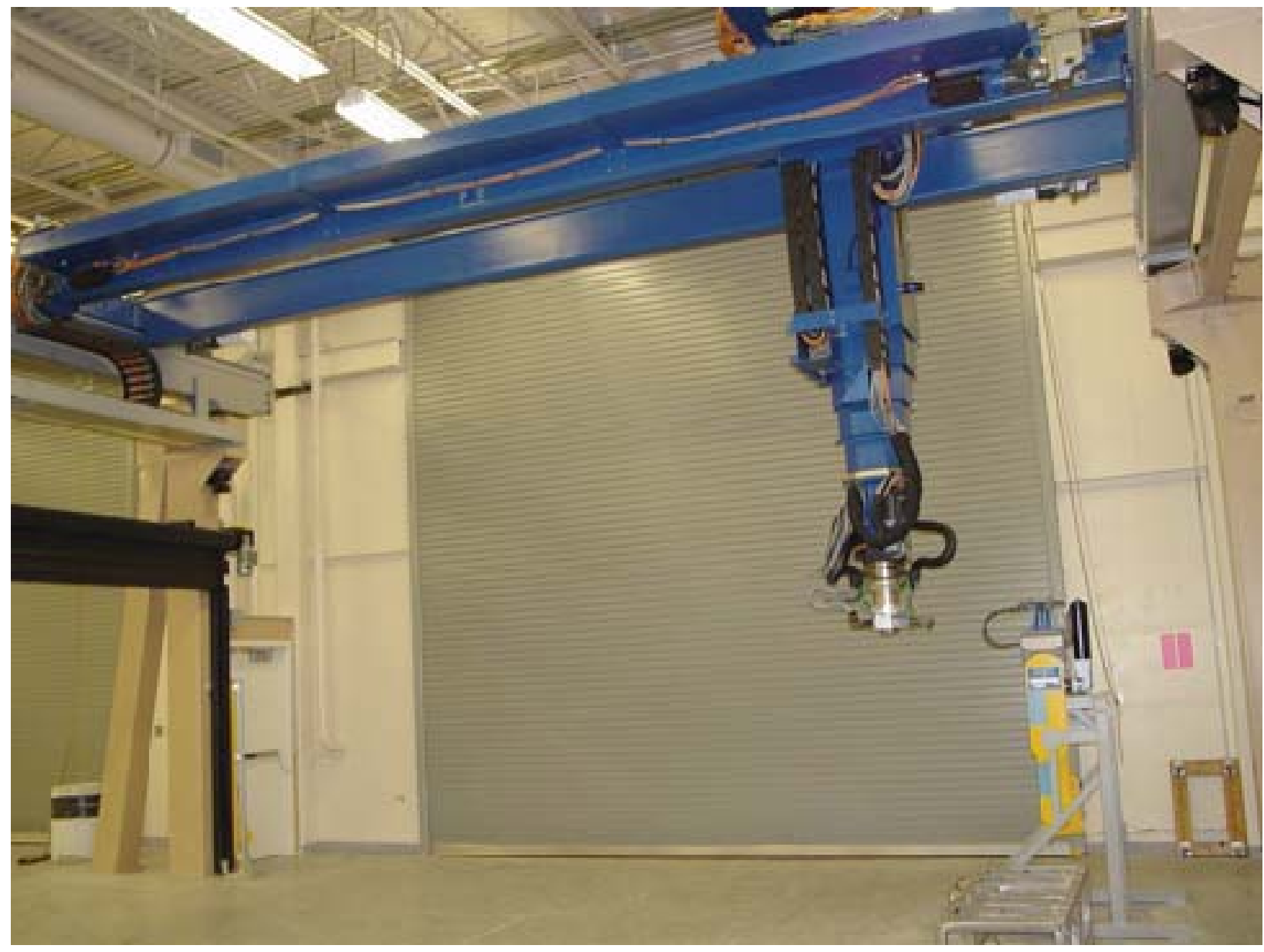

Figure 10 The PaR XR-100 gantry robot and nested 4350 remote manipulator tool 


\subsection{Remote Evaluation}

Specific tooling to interface with the PaR robot was not available for unfastening the spring loaded capture bolts and retracting the screw drive fluid transfer slides on the V-05R prototype. Instead, we opted to use just the lifting hook on the gantry, operated under remote but manual mode. The capture bolts and slides were retracted using hands-on means in order to evaluate the remote handling of the middle contactor unit removal and replacement from the 3 unit prototype. The PaR operator used a remote control and positioned himself in front of and also behind the prototype assembly at a distance of 12 to 20 feet. Several lifts and reinsertions were successfully conducted in the manual mode from both positions. The operator said that these operations, if the PaR was used in preprogrammed place and pick mode, would be well within the capability of the robot without cameras or further modifications to the V05R prototype design. Several views of the contactor lifts and replacements are presented in Figures 1117 on the next pages.

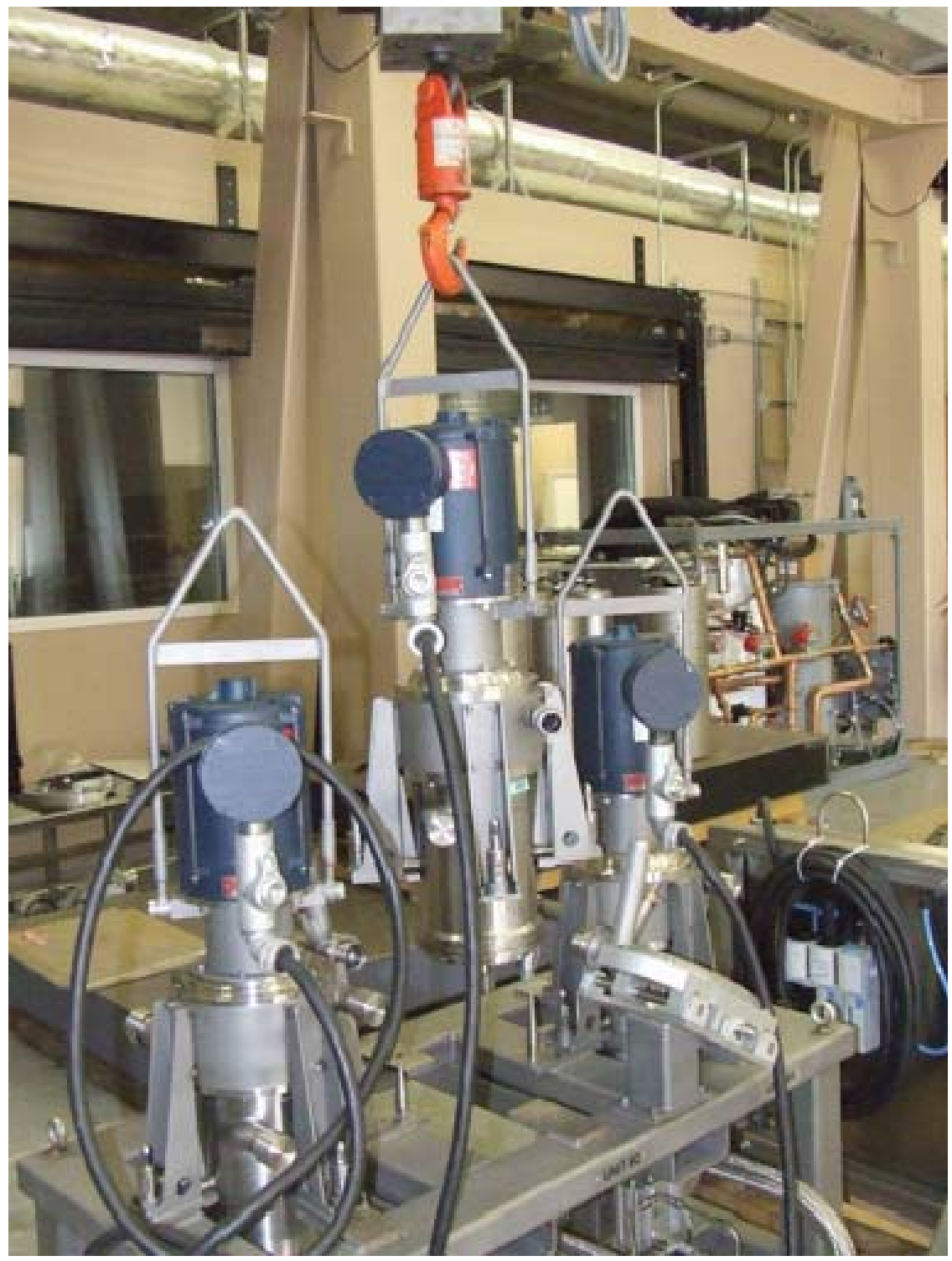

Figure 11 Removal of the middle unit with tapered locating pins visible on the frame 


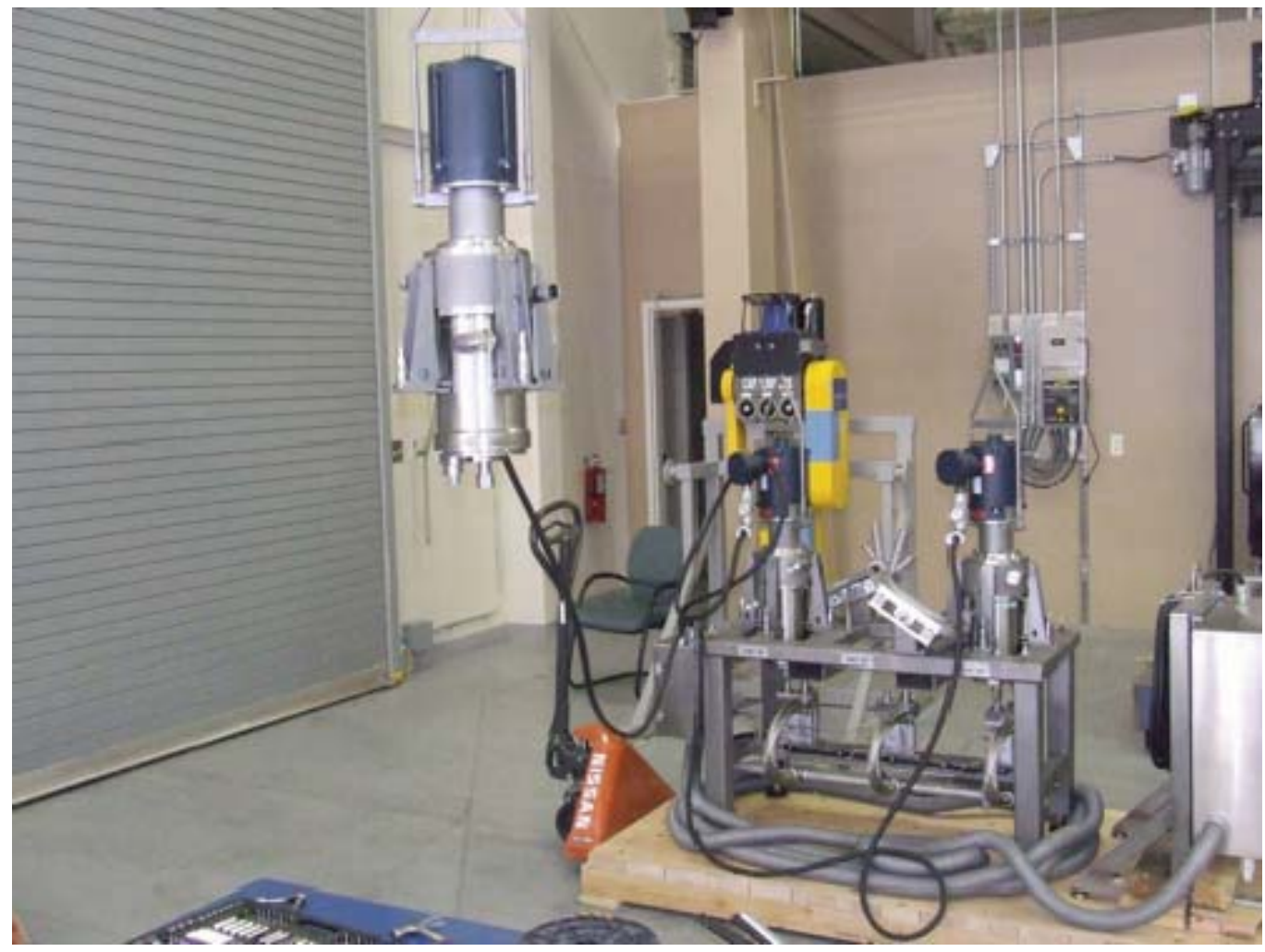

Figure 12 V-05R contactor unit removed from assembly

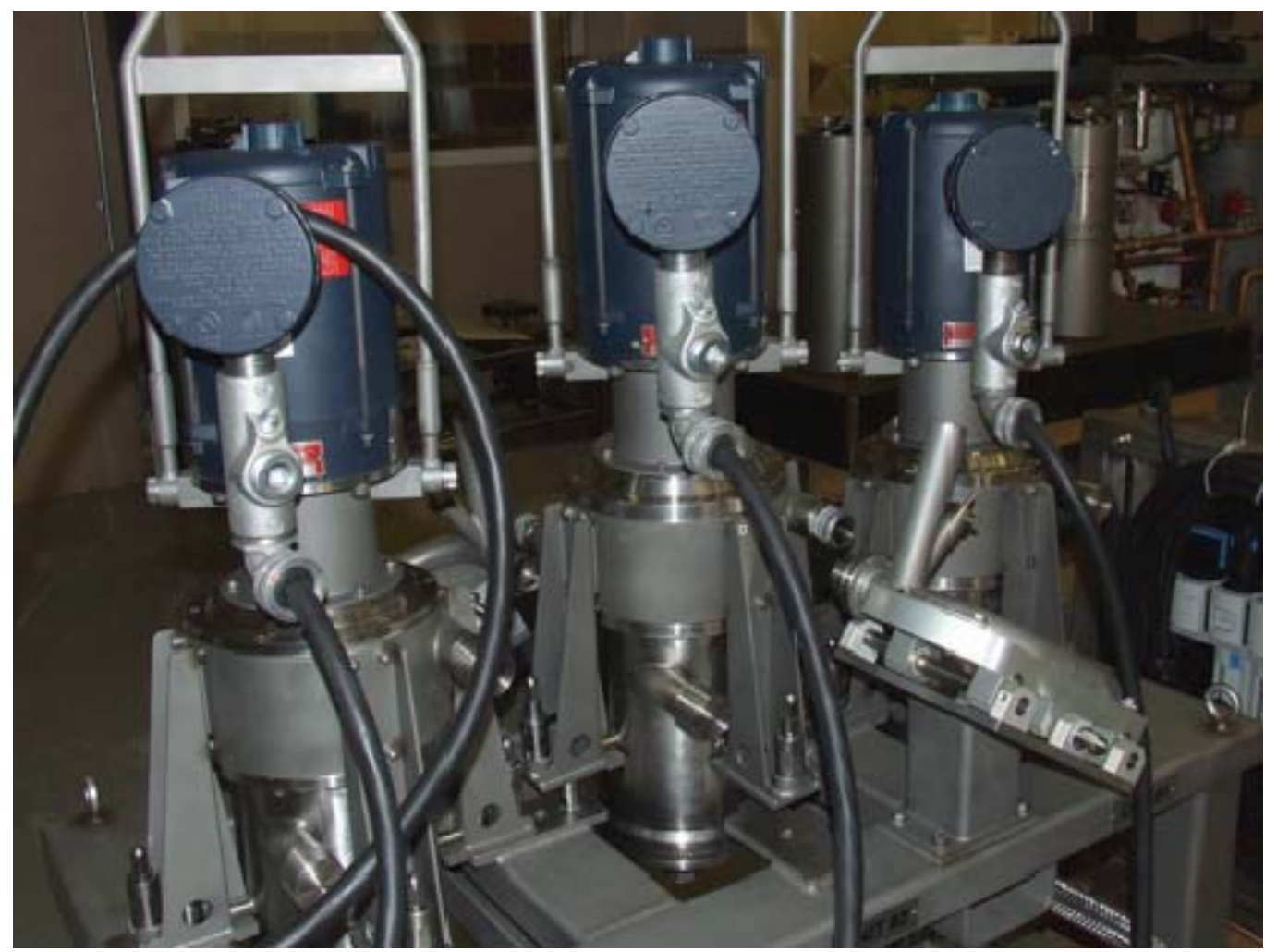

Figure 13 Re-installation with guide pins halfway engaged 


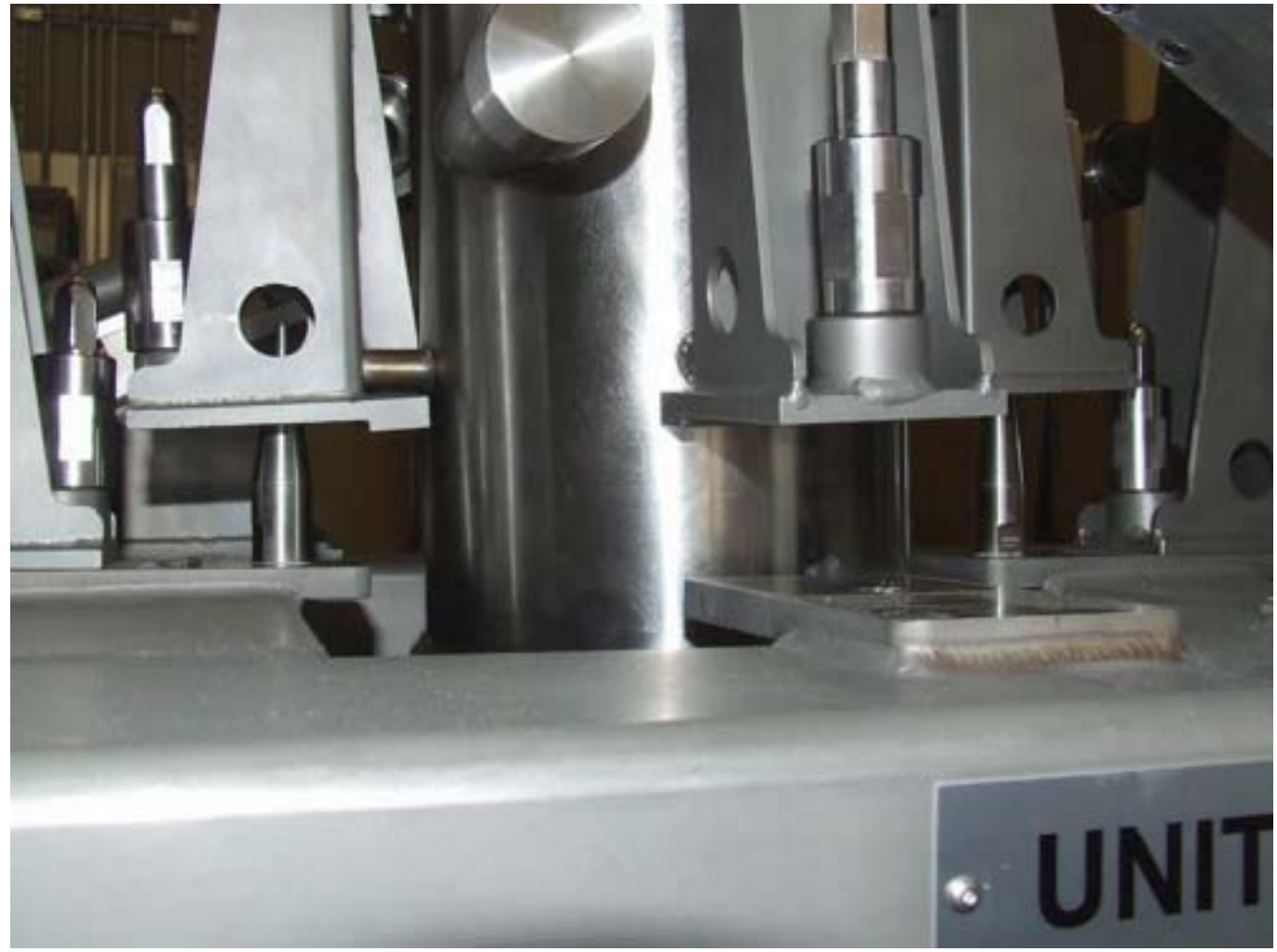

Figure 14 Close up view of guide pins during contactor unit installation

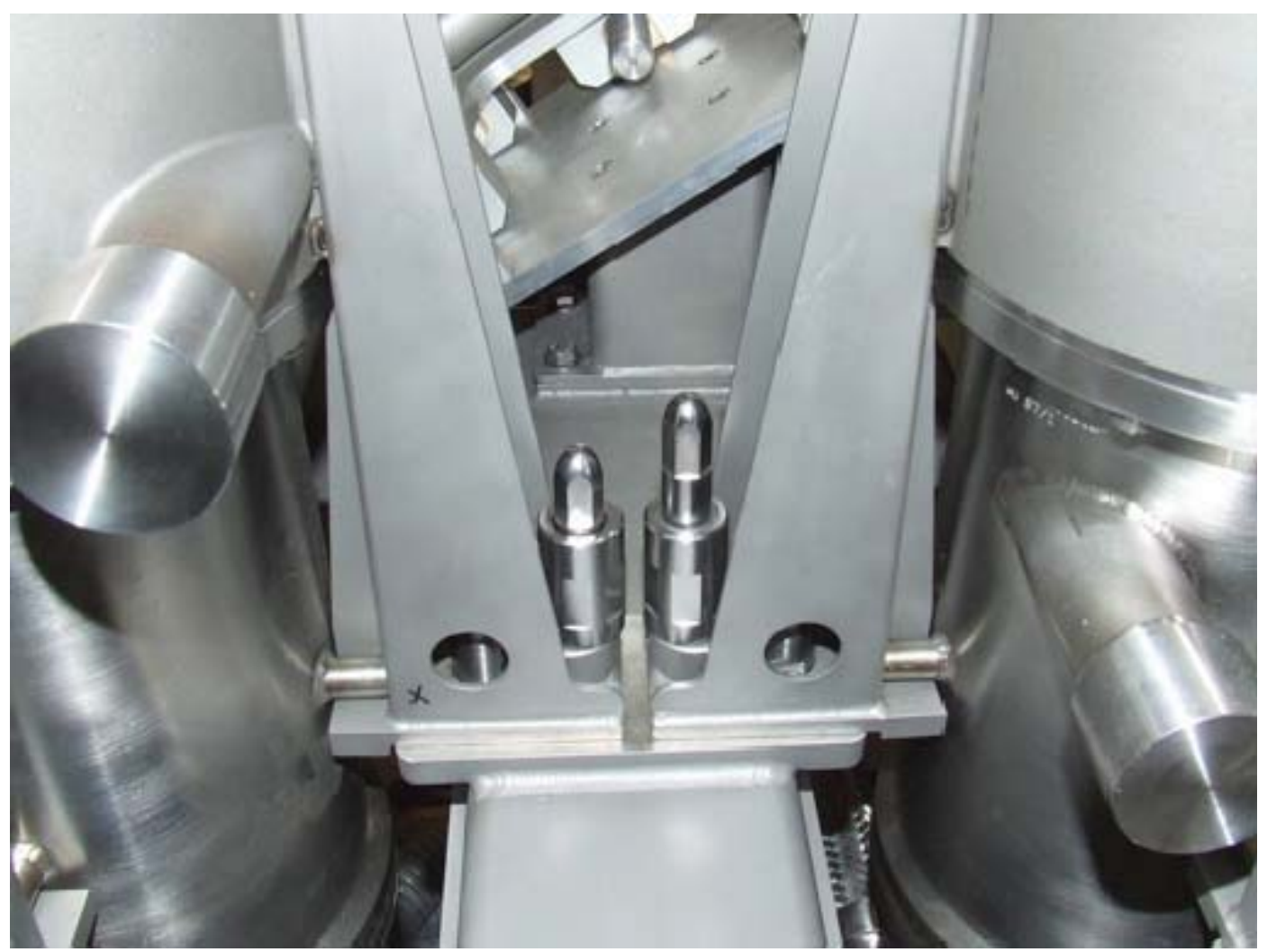

Figure 15 Close up view of spring loaded capture bolts, left one engaged, right one disengaged 


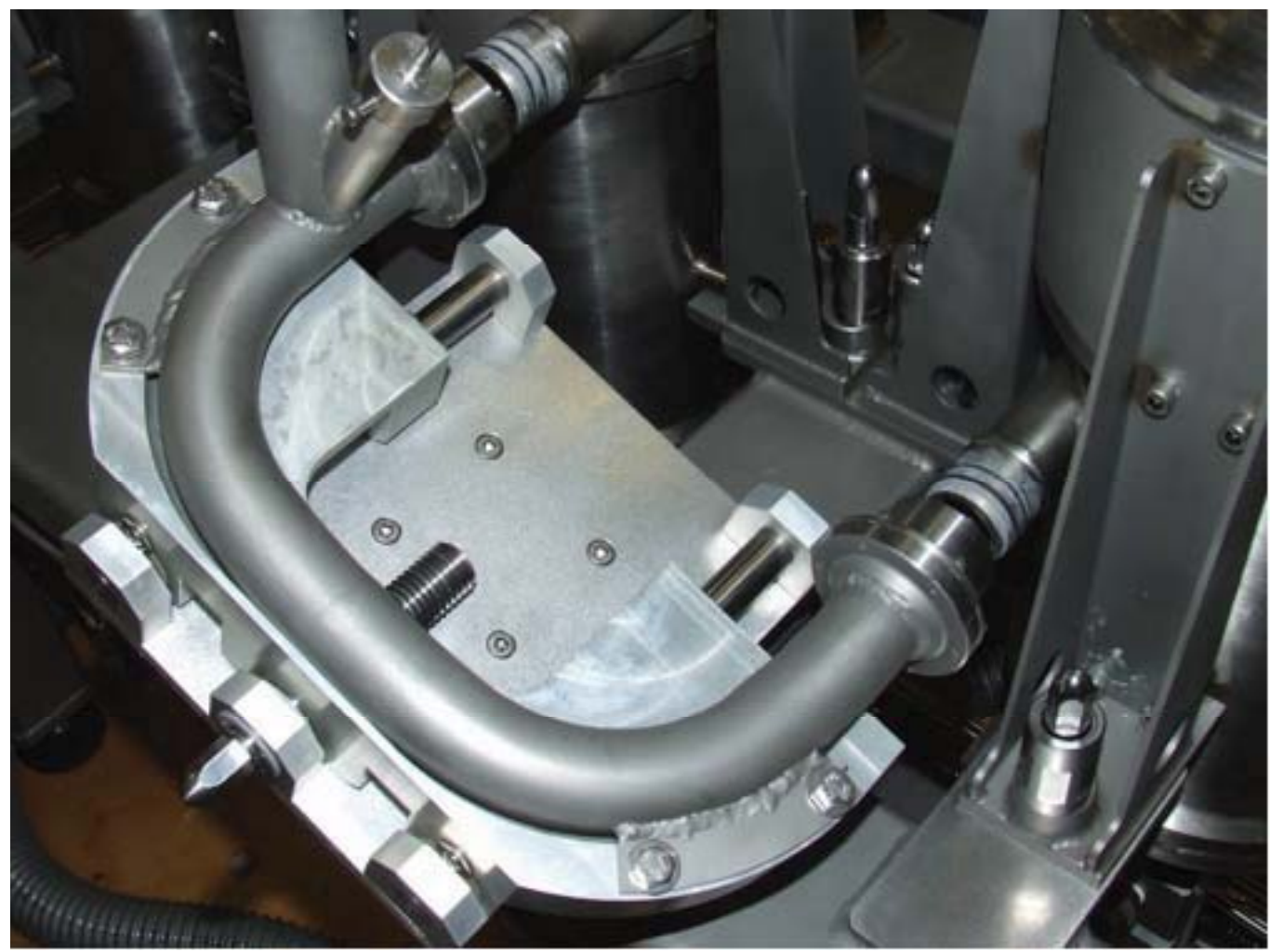

Figure 16 Close up view of fluid transfer slide mechanism and o-ring connectors, disengaged

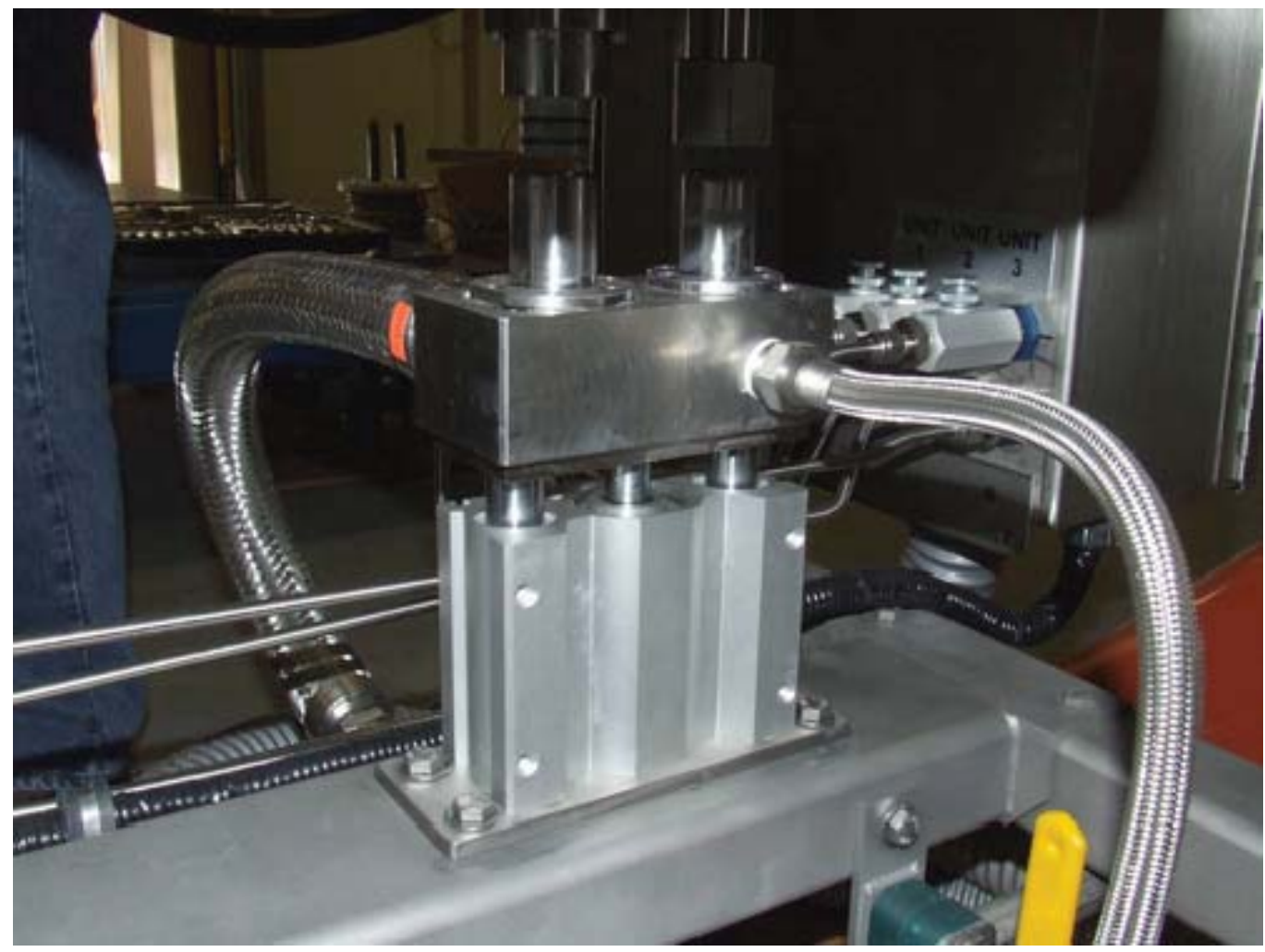

Figure 17 Close up view of the drain (left) and CIP (right) connections and pneumatic driven slide, disengaged 


\section{RESULTS AND DISCUSSION}

Visual observations made during the evaluations revealed that with manual operations and reasonable care, the changeout of a unit with very basic remote handling equipment was not difficult. Several lifts and reinsertions were conducted from both in front of and behind the prototype. For manual operations, the following suggestions were offered:

- Rough guides to help position the unit for reinsertion would simplify the process until the tapered guide pins engage

- It would be visually helpful if the guide pins were located $90^{\circ}$ apart from one another, outside of the mounting brackets, perhaps on the mounting foot plates

- Mounting plates could be moved outward to improve housing clearances from the frame during reinsertion

- A "bolt loose" indicator stripe would also help an operator ensure that all are disengaged before lifting a snubber tool to indicate binding could also be used

- Indication of position for the fluid transfer tube slides or a torque limiter on tool was suggested

- Pneumatic hold down clamps instead of spring loaded capture bolts as used in the V-02R prototype design ${ }^{6}$ would be convenient on units where appropriate

- Lifting bails should be designed to mate with lifting hook diameter and swing a maximum of $90^{\circ}$

\section{CONCLUSIONS}

Both the design and workmanship of the assembly were praised by the remote handling specialists during the evaluation of the V-05R prototype. Lessons learned during the earlier V-02R evaluations ${ }^{6}$ were applied and thus benefited the V-05R final product.

Observations made throughout the manual remote evaluations indicated that the 3 pack V-05R module was a serviceable design for remote handling with typical reprocessing cell remote equipment. Multiple contactor unit change outs were successfully demonstrated with the hook of the PaR gantry. The PaR specialist indicated that all contactor unit lift/reinsertion operations were conducted with little difficulty from either in front of or behind the prototype positions.

A final opinion from another remote handling specialist with many years of manual experience stated that the V-05R prototype assembly was capable of being utilized and maintained in a shielded cell with just two master slave manipulators for service and an electromechanical manipulator for replacement lifts. A single contactor unit, as tested, weighs approximately $60 \mathrm{~kg}$, depending on motor used.

The PaR specialist stated that the XR-100, utilized at full capability, would be an excellent choice for the service and maintenance of the many ACCs required to meet nuclear fuel recycle process separations goals. Via the programming/learning modes, the PaR would be able to change out contactor units by preprogrammed call out using learned steps and geometry without direct operator intervention or visual assistance. Utilizing this technology may allow closer spacing of ACCs in a process cell, thus reducing the cell footprint. Automation of such remote handling operations would provide safe, dependable, and efficient maintenance for a complete aqueous solvent extraction system based on centrifugal contactors. 


\section{REFERENCES}

1. D. H. Meikrantz, J. D. Law, R. S. Herbst, T. G. Garn, N. R. Mann, T. A. Todd, "Hydraulic and Mass Transfer Testing of Commercial $5 \mathrm{~cm}$ Centrifugal Contactors at INL," INL/EXT-05-00793, September 2005.

2. T. G. Garn, N. R. Mann, D. H. Meikrantz, J. D. Law, T. A. Todd, "Hydraulic and Reliability Tests of the CINC V-05TA-CIP $12.5 \mathrm{~cm}$ Annular Centrifugal Contactor," INL/EXT-06-11958, September 2006.

3. T. G. Garn, D. H. Meikrantz, J. D. Law, N. R. Mann, T. A. Todd, "Mass Transfer Efficiency Testing of a Single Stage Commercial $12.5 \mathrm{~cm}$ Annular Centrifugal Contactor at the INL," INL/EXT-07-12739, May 2007.

4. N. R. Mann, T. G. Garn, D. H. Meikrantz, J. D. Law, T. A. Todd, "Clean in Place Testing of a Commercial $12.5 \mathrm{~cm}$ Annular Centrifugal Contactor at the INL," INL/EXT-06-11533, June 2006.

5. T. G. Garn, D. H. Meikrantz, J. D. Law, T. A. Todd, "Hydraulic Verification Testing of a Three-Stage $5 \mathrm{~cm}$ Annular Centrifugal Contactor Remote Design at the INL," INL/EXT-07-13246, September 2007.

6. T. G. Garn, D. H. Meikrantz, J. D. Law, "Remote Evaluation of a Three-Stage $5 \mathrm{~cm}$ Annular Centrifugal Contactor Remote Module at the INL," INL/EXT-08-13670, January 2008. 